\title{
A CHAPA PERDEU, E AGORA? O CASO DA EMPRESA PONTO CERTO EQUIPAMENTOS DE INFORMÁTICA
}

\author{
THE PLATE LOST, WHAT NOW? \\ THE CASE OF COMPANY PONTO CERTO COMPUTER EQUIPMENT \\ Amanda Paterno Sbissa \\ Mestre em Administração pelo Programa de Pós-graduação em Administração da Universidade do Vale do \\ Itajaí (PPGA/UNIVALI) \\ Biguaçu, SC, Brasil \\ E-mail: amandapaternosbissa@gmail.com
}

Patrinês Aparecida França Zonatto*

Doutoranda em Administração pelo Programa de Pós-graduação em Administração da Universidade do Vale do Itajaí (PPGA/UNIVALI)

Biguaçu, SC, Brasil

E-mail: patrineszonatto@gmail.com

Sidnei Vieira Marinho

Professor do Programa de Pós-Graduação em Administração (PPGA) e do Programa de Mestrado

Profissional em Gestão Empresarial, Internacionalização e Logística (PMPGIL) da Universidade do Vale do

Itajaí (UNIVALI)

Biguaçu, SC, Brasil

E-mail: sidnei@univali.br

Anete Alberton

Professora do Programa de Pós-Graduação em Administração (PPGA) e do Programa de Mestrado

Profissional em Gestão Empresarial, Internacionalização e Logística (PMPGIL) da Universidade do Vale do

Itajaí (UNIVALI)

Biguaçu, SC, Brasil

E-mail: anete@univali.br

\section{RESUMO}

Este caso de ensino apresenta as estratégias de negócios adotadas por uma pequena empresa de equipamentos eletrônicos, em um contexto de interferências políticas, decorrentes de mudanças vivenciadas a cada troca de gestão do seu principal cliente. A empresa, denominada neste estudo como Ponto Certo, necessitou se reposicionar no mercado frente ao impacto de tais mudanças. Situações como estas estão presentes no cotidiano de muitas empresas, que, quando ocorrem, precisam se posicionar e alinhar suas estratégias de negócios frente a um ambiente organizacional com grandes mudanças políticas, sociais, tecnológicas e culturais. Nestes casos, as grandes decisões referentes a essas mudanças ficam a cargo do proprietário ou gestor principal da organização, que objetiva o crescimento e desenvolvimento de sua empresa. $O$ caso possibilita ao professor explorar temas como estratégia empresarial, mudança organizacional e tomada de decisões estratégicas. Após a análise da situação apresentada, os alunos são convidados a discutir sobre o papel do gestor, propondo estratégias para a tomada de decisão. O caso é finalizado com notas de ensino e sugestões de aplicação em aula.

Palavras-chave: Estratégias de negócios. Mudança organizacional. Tomada de decisão.

\section{ABSTRACT}

This teaching case presents the business strategies adopted by a small business electronic equipment, in a context of political interference, resulting from changes experienced at each change of its main customer management. The company named in this study as Ponto Certo, needed to reposition itself in the market with the impact of such changes. Situations like these are present in the daily lives of many companies, which, when they occur, need to position and align their business strategies forward to an organizational environment with great political, social, technological and cultural. In such cases, the major decisions related to these changes are borne by the owner or top manager of the organization, which aims at the growth and development of your company. The case enables the teacher to explore issues such as corporate strategy, organizational change and strategic decision making. After analyzing the situation presented, students are invited to discuss the role of the manager, proposing strategies for decision making. The case is finished with teaching notes and application suggestions in class.

Keywords: Business strategies. Organizational change. Decision making.

Data de aprovação: 29 de março de 2016.

Data de submissão: 20 de dezembro de 2015. 


\section{ORIGENS DA EMPRESA}

Leandro nasceu em uma família com histórico empreendedor. O seu pai era um empresário bemsucedido, embora já tivesse enfrentado diversas crises financeiras em seus negócios. Apesar ter de enfrentar uma traumática falência em sua antiga empresa que atuava no ramo de comércio exterior, Leandro partiu em busca de outra área de atuação profissional.

Assim, para identificar uma possibilidade de atuação, Leandro procurou em sua antiga empresa, quais eram os produtos de maior procura pelos seus clientes e assim verificou que "Equipamentos de informática" correspondiam a categoria em que incidia a maior demanda por parte de seus antigos clientes.

Deste modo, apesar de abalado e de preocupado com a sua situação financeira que piorou muito com o término da antiga empresa, Leandro constituiu no ano de 1995 uma nova empresa, denominada Ponto Certo Equipamentos de Informática Ltda. A Ponto Certo surgiu com uma ousada missão: "Ser uma empresa referência em locação de equipamentos de impressão, copiadoras e em atendimento técnico especializado, oferecendo produtos e serviços confiáveis e competitivos que atendam às necessidades dos clientes".

No início a empresa contava apenas com o trabalho e a dedicação de um técnico e do próprio proprietário. Aos poucos, como era o grande sonho de Leandro, a empresa foi crescendo e se desenvolvendo, tornando-se referência no mercado em que atuava.

\section{A EMPRESA PONTO CERTO}

A empresa Ponto Certo é especializada em locação de impressoras e copiadoras. Possui experiência consolidada de aproximadamente 20 anos de atuação neste segmento, atuando principalmente na região Sul do Brasil. Por atuar no segmento de locação e manutenção de equipamentos de impressões e cópias, a empresa oferece inovação aos seus clientes, caracterizando-se como uma oportunidade para a redução de custos de impressões as empresas contratantes. A empresa trabalha com locação de impressoras e copiadoras de marcas renomadas no mercado, oferecendo os melhores equipamentos tecnológicos aos seus clientes, sem que estes tenham que realizar um grande investimento na compra de novos equipamentos de cópias e impressão. A empresa durante o período de atuação buscou oferecer agilidade e eficiência atuando como parceira de seus clientes, prestando acompanhamento técnico especializado, realizando a manutenção periódica dos equipamentos, além de primar pelo atendimento imediato de suas demandas.

A empresa conta com uma equipe de dezesseis funcionários. A estrutura administrativa da empresa é formada por três colaboradores, sendo um responsável pela parte administrativa e de gestão de pessoas, outro responsável pela parte financeira e o terceiro colaborador atua na parte de relacionamento com os clientes e em serviços administrativos operacionais de escritório. A prospecção de clientes e a aquisição de novos equipamentos são efetuadas pelo próprio dono da empresa que não possui formação superior relacionada à área de atividade em que atua. $O$ restante do quadro funcional se compõe de uma secretaria $e$ técnicos de manutenção de equipamentos.

A sede da empresa está localizada na cidade de Porto Alegre/RS e ela atende principalmente a região Metropolitana desta cidade que reúne aproximadamente trinta municípios. 


\section{O RUMO DA EMPRESA PONTO CERTO COM A PROSPECÇÃO DA JRD/RS}

Como possuía uma ampla rede de relacionamentos, Leandro começou a firmar bons contratos para locação de impressoras e copiadoras. Um desses contratos foi efetivado em $2006 \mathrm{com}$ a JRD/RS uma entidade de classe, que possui em sua hierarquia como cargo de maior representação "a presidência", cargo eletivo com mandato de quatro anos podendo uma única reeleição. O presidente da JRD/RS era amigo pessoal de Leandro e não foi difícil prospectar esse excelente novo cliente. Como a JRD/RS possuía unidades de atuação em várias cidades do Estado do Rio Grande do Sul, a JRD passou a ser a principal cliente da Ponto Certo, fazendo dobrar seu faturamento.

Confiante em seu bom faturamento, Leandro pensou que já era hora de começar "a colher seus frutos" e não via mais a necessidade de prospectar novos clientes, pois a JDR/RS supria toda a demanda de sua empresa. Com o passar do tempo a JRD/RS passou a ser a principal fonte de recursos da empresa Ponto Certo, como se pode observar na Tabela 1.

Tabela 1: Faturamento semestral da Ponto Certo

\begin{tabular}{c|c|c|c|c|c}
\hline Período & $\begin{array}{c}\text { Faturamento com } \\
\text { Cliente JRD/RS }\end{array}$ & $\begin{array}{c}\text { Participação } \\
\text { no } \\
\text { Faturamento } \\
\text { Total }\end{array}$ & $\begin{array}{c}\text { Faturamento } \\
\text { com Demais } \\
\text { Clientes }\end{array}$ & $\begin{array}{c}\text { Participação } \\
\text { no } \\
\text { Faturamento } \\
\text { Total }\end{array}$ & $\begin{array}{c}\text { Total do } \\
\text { Faturamento }\end{array}$ \\
\hline Janeiro & $\mathrm{R} \$ 41.203,78$ & $60,06 \%$ & $\mathrm{R} \$ 27.403,00$ & $39,94 \%$ & $\mathrm{R} \$ 68.606,78$ \\
\hline Fevereiro & $\mathrm{R} \$ 46.302,65$ & $61,24 \%$ & $\mathrm{R} \$ 29.304,89$ & $38,76 \%$ & $\mathrm{R} \$ 75.607,54$ \\
\hline Março & $\mathrm{R} \$ 54.471,40$ & $64,39 \%$ & $\mathrm{R} \$ 30.119,50$ & $35,61 \%$ & $\mathrm{R} \$ 84.590,90$ \\
\hline Abril & $\mathrm{R} \$ 53.997,00$ & $57,45 \%$ & $\mathrm{R} \$ 39.992,89$ & $42,55 \%$ & $\mathrm{R} \$ 93.989,89$ \\
\hline Maio & $\mathrm{R} \$ 47.121,32$ & $53,33 \%$ & $\mathrm{R} \$ 41.231,54$ & $46,67 \%$ & $\mathrm{R} \$ 88.352,86$ \\
\hline Junho & $\mathrm{R} \$ 60.100,20$ & $59,98 \%$ & $\mathrm{R} \$ 40.100,70$ & $40,02 \%$ & $\mathrm{R} \$ 100.200,90$ \\
\hline
\end{tabular}

Fonte: Adaptado de Relatórios Gerenciais da Empresa Ponto Certo Equipamentos (exercício 2012).

Leandro sentia prazer em atender as solicitações da JRD/RS e as fazia pessoalmente. Assim, cada vez mais a JRD/RS solicitava prestações de serviços da empresa Ponto Certo, que tinha cada vez menos tempo para se dedicar a prospecção de novos clientes. Apesar de buscar atender a todos os municípios da região Metropolitana de Porto Alegre, desde que passou a atender a JRD/RS a Ponto Certo não priorizou mais investir em captação de novos clientes.

Ao final de 2013 o contrato da empresa Ponto Certo com a JRD/RS já estava em seu sétimo ano. Ao longo desse período, a Ponto Certo foi crescendo e se consolidando. Contudo, sua receita dependia majoritariamente da parceria estabelecida com a JRD/RS que em 2014 teria eleição para o novo presidente. Neste caso, tendo em vista que seu amigo pessoal já estava no seu segundo mandato, o mesmo não poderia mais concorrer à presidência. 


\section{CHEGOU O DIA DA ELEIÇÃO}

Era domingo de manhã, Leandro acorda, toma seu café e lê o seu jornal. A apreensão tomava conta, pois era o dia da eleição para presidente da JRD/RS. Além disso, Leandro se sentia responsável pela garantia do sustento de seus funcionários e de suas famílias. Na tentativa de diminuir sua angústia, sua esposa convida-o para almoçar na casa de um amigo.

Durante o almoço, Leandro não conseguia parar de pensar na eleição da nova presidência da JRD/RS, pois estava claro que o resultado da eleição poderia causar um impacto muito negativo na empresa Ponto Certo, vindo destruir o que com muito esforço havia sido realizado, que resultou no fortalecimento e na consolidação da empresa.

Eram 15hs horas quando o telefone de Leandro tocou. Era Emanuel, amigo e companheiro de chapa da eleição da JRD/RS, avisando que passaria para pegar Leandro para que eles fossem juntos acompanhar a votação.

Chegou a hora da votação, muito movimento, cada um defendendo a sua chapa. Leandro por sua vez, não poderia estar mais nervoso e preocupado com futuro da empresa e de seus colaboradores. Eram quase $17 \mathrm{hs}$ horas quado saiu o resultado. O presidente eleito não era o canditado da chapa que Leandro apoiava. A decepção foi total.

\section{A CHAPA PERDEU, E AGORA?}

Era manhã de segunda feira, um dia cinzento, o sol resolveu não aparecer. Leandro chega em sua empresa, abre sua porta de vidro e recolhe o jornal. O dia estava diferente, a empresa que já se encontrava em uma situação estável no mercado passou a estar em uma situação de risco. A JRD/RS, seu principal cliente, responsável por mais da metade de seu faturamento, estava sob uma nova administração.

E não era difícil de imaginar que o novo presidente iria escolher seus próprios fornecedores. Afinal, durante todo o processo eleitoral Leandro deixou muito claro que estava apoiando o outro canditado, que tinha sido derrotado na eleição. E agora, como a Ponto Certo iria sobreviver sem seu principal cliente?

\section{NOVOS RUMOS}

Leandro sabe que precisa seguir em frente. Além disso, ele tinha responsabilidade com colaboradores que dependiam totalmente da empresa para sustentarem suas famílias. A empresa não poderia encerar suas atividades.

Mas Leandro não se sentia seguro em investir em um momento de novas mudanças. Além disso, sentia medo de que essas mudanças poderiam não trazer o retorno esperado. 0 empresário bem-sucedido que até então levava uma vida tranquila na cidade onde morava, pensava que se tomasse a decisão errada poderia acabar com o sonho que era sua empresa.

Muitas coisas passavam pela cabeça de Leandro. Muitas dúvidas surgiam, pois já não era mais tão novo, a idade já avançava e nunca tinha concluído um curso superior. Então pensava: Como vou fazer para conseguir renovar o contrato com a JRD/RS com essa nova administração? Caso não consiga renovar o 
contrato, como vou conseguir honrar meus compromissos financeiros? E se fechar a empresa vou trabalhar onde? E por consequência, como vou sustentar minha família? E mesmo que conseguisse um emprego, será que conseguiria ganhar o mesmo valor que atualmente retirava mensalmente na empresa? Além disso, como faria para reiniciar tudo de novo, uma vez que a empresa se encontrava em uma situação favorável? Para prospectar novos clientes teria que enfrentar a concorrência?

Enfim, inúmeras coisas vinham à mente de Leandro. Pensava que se permanecesse na situação atual, sua empresa teria dificuldades de se manter no mercado que apresentava uma concorrência cada vez mais acirrada.

Quando a empresa Ponto Certo foi fundada, não possuía muitos concorrentes. Agora, quase vinte anos depois, o número de empresas competindo no mesmo segmento triplicou. Leandro sabia que precisaria tomar uma decisão para atingir novos rumos para a empresa e a decisão precisaria ser tomada com urgência, mas com muita eficiência. E agora... que decisão Leandro deve tomar? 


\section{NOTAS DE ENSINO}

\section{Obtenção dos dados}

As informações descritas no texto foram coletadas a partir de entrevistas junto ao proprietário da empresa. O nome da empresa, da entidade e dos personagens citados no texto foram alterados para preservar a identidade do caso real.

\section{Utilização recomendada}

O caso de ensino foi elaborado para aplicação principalmente com alunos de graduação no curso de administração, preferencialmente nas disciplinas gestão empresarial, teorias da administração, administração mercadológica e estratégias organizacionais.

\section{Objetivos de Aprendizagem}

O caso de ensino apresenta uma situação em que o gestor deve tomar uma decisão importante, desta forma pode-se destacar alguns temas de aprendizagem:

a) Propiciar reflexões sobre situações que permitam ao participante identificar conceitos necessários para a tomada de decisão estratégica;

b) Debater sobre as dificuldades e as resistências enfrentadas durante o processo de mudança organizacional; e,

c) Estimular nos alunos a importância de alguns pontos fundamentais a serem considerados para apoio na tomada de decisão;

\section{Questões para discussão do caso em sala de aula}

Relacionando ao caso para ensino, sugerem-se as seguintes questões para discussão:

1. A partir da análise do caso, quais fatores estão influenciando a necessidade de rápidas mudanças na empresa Ponto Certo?

2. Quais resistências e obstáculos o gestor possivelmente terá que enfrentar para alcançar as mudanças que a empresa necessita?

3. Discuta qual seria a sua sugestão de escolha estratégica com relação ao futuro da empresa Ponto Certo?

4. Quais os principais motivos que levaram a empresa Ponto Certo a chegar nesta encruzilhada? 


\section{Sugestão para a compreensão e análise do caso}

Como sugestão para a compreensão e análise do caso pelo professor, para que se possa orientar a discussão em sala de aula, aconselha-se a adoção dos seguintes procedimentos:
a) Leitura prévia: realizada pelo aluno antes da aula
b) Tempo para análise de todo o caso: duas horas aproximadamente
c) Análise e discussão dos alunos em grupos de no máximo 4 pessoas (30 minutos)
d) Discussão orientada pelo professor (1 hora)
e) Fechamento da discussão do caso pelo docente (20 a 30 minutos) 


\section{ABORDAGENS TEÓRICAS RECOMENDADAS}

\section{Mudança Organizacional}

As empresas são cada vez mais impulsionadas à busca de inovação, estratégias de diversificação e ampliação dos seus resultados, diante da competitividade com seus concorrentes. Isso configura um ambiente de grande dinamismo e motiva as organizações a estarem em constante adaptação às novas condições do mercado (ROBBINS, 2009). Nesta perspectiva, observa-se que a empresa Ponto Certo está passando pela mesma situação. Devido ao ambiente de grandes incertezas, ela precisa se adequar a este dinamismo ou estará fora do mercado, dando espaço para que seus concorrentes ocupem uma fatia maior do mercado de locação e manutenção de equipamentos para impressões e cópias.

Na visão de Rondeau (1999), as organizações estão em constante transformação, porque a forma de pensar do gestor também se transforma com o decorrer do tempo. Podemos compreender mudança organizacional como sendo qualquer alteração na estrutura empresarial, seja está planejada ou não, ou ainda nas relações que envolvam a empresa e seu ambiente de atuação, que promovam a sustentabilidade de suas ações organizacionais (LIMA; BRESSAN, 2003). Vergara (2000) estabelece que o principal desafio das organizações está em gerenciar o processo de mudança organizacional, pois essa mudança em uma empresa não se limita a procedimentos, técnicas e políticas, mas se refere a uma alteração de atitudes e comportamentos, envolvendo indivíduos e equipes.

Kurt Lewin citado no livro de Robbins (2009) estabeleceu um dos primeiros modelos teóricos a respeito do tema mudança organizacional. O autor propõe um processo de mudança em três etapas, argumentando que para uma mudança organizacional ter sucesso, deve ser baseada nas etapas de: descongelamento, movimento e recongelamento. A Figura 1 apresenta o modelo de três etapas proposto por Lewin.

\section{Figura 1: Modelo de Mudança de Kurt Lewin}

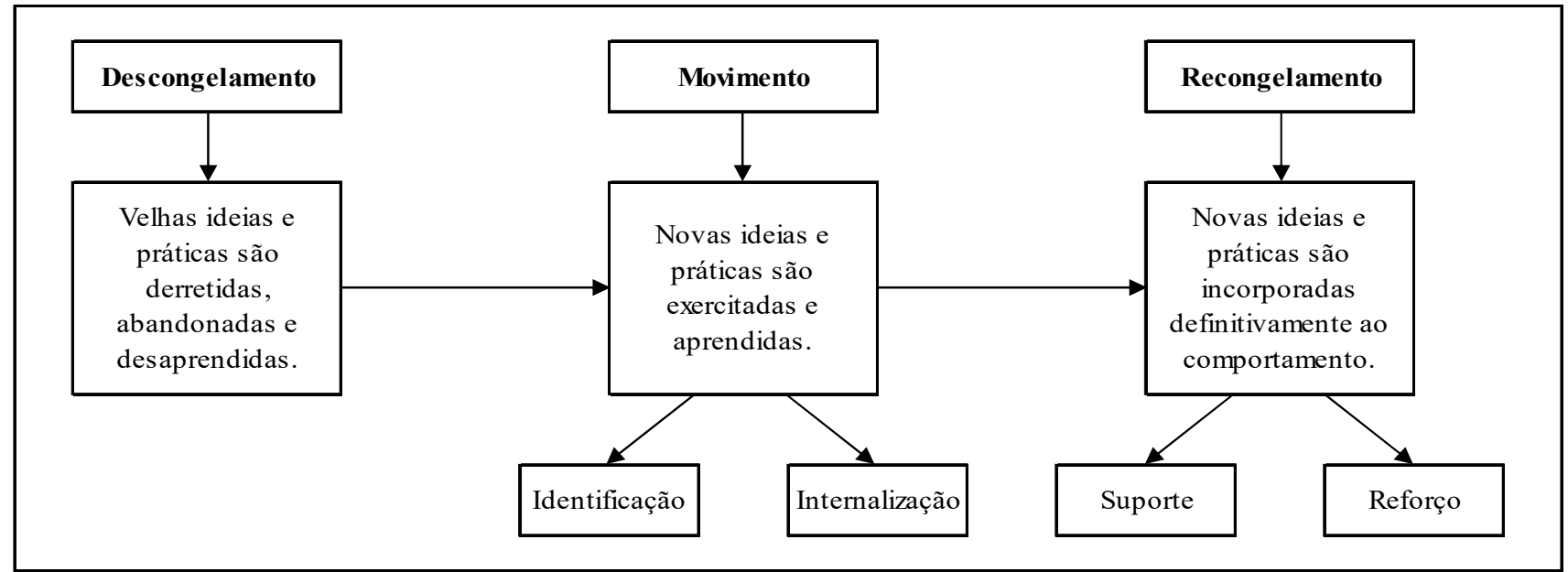

Fonte: Adaptado de Robbins (2009, p. 262) 
Segundo Robbins (2009), as mudanças em uma empresa primeiro passam pelo processo de abandono de velhas práticas. Esse abandono é denominado pelo autor de "descongelamento". Após o descongelamento, a empresa passa a adotar novas ideias. Neste momento, a implementação destas novas ideias passa a ser consolidada pela empresa e são incorporadas. Por fim, torna-se necessário que essa nova situação precise "recongelar" para que se sustente, o que caracteriza a terceira etapa da mudança organizacional, segundo o autor.

No âmbito organizacional, Chiavenatto (2003) explica que a mudança da velha ideia para a nova pode enfrentar duas situações distintas, sendo estas denominadas de forças positivas e forças negativas. As forças positivas estão relacionadas a fatores que apoiam o processo de mudança, contribuindo para que esta aconteça de forma bem-sucedida. Em contrapartida, as forças negativas são restrições a mudança, estando relacionadas a oposição e resistências a mesma. Tais forças podem dificultar a tentativa de mudança, tornando-a malsucedida.

Assim, a mudança organizacional se estabelece como um processo em que para cada uma das fases da mudança torna-se necessário o desenvolvimento de ações com o propósito de identificar fatores chaves para o seu sucesso. Tais ações devem ser geridas diretamente pelos responsáveis pela sua implantação.

Concordando com essa visão proposta por Lewin, Robbins (2009) argumenta que as organizações buscam novos posicionamentos, com maior estabilidade nos seus negócios, dentro do mercado em que estão inseridas. As organizações que estão em ambientes competitivos precisam realizar movimentos de mudança como parte da sua dinâmica de administração. Contudo, o autor destaca que tanto as empresas quanto os indivíduos que atuam nas organizações tendem a resistir às mudanças.

Como ocorreu com a empresa Ponto Certo durante todos os anos de atividade, sua despreocupação em captar novos clientes gerou uma dependência apenas da JRD/RS. Mesmo vivendo em um ambiente de incerteza, o gestor não foi preciso quanto a avaliação de possíveis mudanças que poderiam ocorrer e impactar a organização, se acomodando da maneira como vinha trabalhando, uma vez que até então, estava obtendo o retorno esperado.

Sendo assim, percebe-se que o processo de implantação de novas ideias necessita ser estimulado em uma empresa, uma vez que por meio deste torna-se possível o compartilhamento de informações e a identificação de novas oportunidades ou ameaças ao negócio, sobre as quais os gestores poderão atuar visando amenizar o impacto negativo de determinadas ameaças e viabilizar a atuação da empresa frente as novas oportunidades identificadas. Portanto, a implantação de novas ideias pode contribuir para o fortalecimento da organização.

Após a mudança e o realinhamento dos objetivos organizacionais, torna-se necessária à sua disseminação na organização. Neste caso em específico, é significativo ser enfatizado os aspectos positivos decorrentes da mudança e que esta ocorrerá respeitando-se o tempo necessário de adequação (AVEY; WERNSING; LUTHANS, 2008), mas com vistas a fortalecer a organização, gerando novas oportunidades de emprego e renda.

Evidentemente que algumas mudanças têm por base situações emergentes, decorrentes do ambiente de mercado em que se encontra esta empresa, por exemplo. Neste caso, em um número significativo de vezes não é possível se respeitar o tempo de adequação (AMBURGEY; KELLY; BARNETT, 1990), razão pela qual decisões são tomadas, mesmo que estas possam não ser consideradas as mais adequadas. 
Além disso, a tomada de decisão referente à necessidade de enxugamento do quadro de colaboradores trará insegurança e possível descontentamento, podendo gerar até mesmo instabilidade no ambiente da empresa. Entretanto, os trabalhadores que forem mantidos precisam ser acompanhados e cuidados para compreenderem com clareza as causas das demissões, assim como o porquê das mudanças e sua manutenção no quadro de colaboradores da empresa. Em específico, é importante possibilitar aos colaboradores que permanecerem no quadro da empresa a "garantia de liberdade" para exporem suas angústias, sem que estes se sintam ameaçados (KIEFER, 2002). Tais ações podem contribuir para a melhoria dos níveis de produtividade.

Este posicionamento receptivo e acolhedor por parte da diretoria executiva poderá facilitar o processo de mudança organizacional a curto, médio e em longo prazo. Portanto, compreende-se que a mudança organizacional precisa ser mediada com significativa cautela e que o gestor necessita preparar-se para trabalhar com as possíveis situações de resistências e sofrimentos inerentes a este processo. Uma vez que a mudança se caracteriza como um processo demorado e frágil, em que o gestor precisa estar apto a contornar a situação da melhor forma possível para que não ocorram prejuízos financeiros para a organização, tal acompanhamento é essencial para o êxito da mudança.

Como pode-se observar no caso da empresa Ponto Certo, diante de uma grande mudança que aconteceu, Leandro, gestor da empresa, precisou utilizar de todo seu conhecimento e expertise para atuar com tal situação para que não acarretasse danos à empresa.

\section{A Tomada de Decisões Estratégicas}

As empresas enfrentam grandes mudanças que podem afetar seu desempenho frente a um mercado altamente competitivo. Deste modo, constantemente gestores se deparam com a necessidade da tomada de decisões estratégicas. Entende-se como decisões estratégicas as decisões de médio e longo prazo que englobam as decisões de investimento, financiamento e distribuição de dividendos, as quais têm que ser consideradas de forma interdependente (NETO, 1997).

De acordo com Ansoff (1977, p. 30), "no processo de tomada de decisão, existem vários enfoques sobre decisões empresarias individuais ou em grupo. Decisões estratégicas tendem a ser tomadas por esses grupos". Na visão de Hall (2004), as "decisões estratégicas" podem ser definidas como as decisões de alto risco que ocorrem no mais alto escalão das organizações. $O$ autor afirma ainda que este processo abrange a abertura de novos mercados, bem como o desenvolvimento de novos produtos ou serviços. Desta forma, o processo de tomada de decisão dentro de uma organização pode relacionar-se à abertura de novos horizontes nas áreas de pessoal, prioridades, programas e iniciativas organizacionais.

Tomar decisões na visão de Caravantes, Panno e Kloeckner (2005, p. 446) é o "processo de escolher uma dentre um conjunto de alternativas. Cabe ao tomador de decisão reconhecer e diagnosticar a situação, gerar alternativas, avaliar as alternativas, selecionar a melhor alternativa, implementar a alternativa escolhida e avaliar os resultados". Neste sentido, nota-se que a tomada de decisão está relacionada ao gestor que precisa ter visão para prever o problema e trabalhar para que sua decisão possa contribuir com o desempenho da empresa. 
Conforme explica Maximiano (2009), decisões são tomadas para determinar problemas ou aproveitar oportunidades. O processo de tomar decisão começa com uma situação de frustração, interesse, desafio, curiosidade ou irritação. Há um objetivo a ser alcançado ou um fato que está ocorrendo que exige algum tipo de ação. Nestes casos, podem haver obstáculos ou uma condição que se deve corrigir estimulando a tomada de decisão, ou ainda a busca pela viabilização de uma oportunidade de negócios que pode ser aproveitada.

Nesta perspectiva Robbins et al. (2010, p. 167) destacam que "a tomada de decisão ocorre em reação a um problema. Um problema existe quando se verifica uma discrepância entre o estado atual das coisas e seu estado desejável". O autor ressalta ainda que tomada de decisão envolve seis elementos básicos, sendo estes:

1) o tomador de decisão: é a pessoa que faz uma escolha ou opção entre várias alternativas futuras de ação;

2) os objetivos: são o que o tomador de decisão pretende alcançar com suas ações;

3) as preferências: são os critérios que o tomador de decisão usa para fazer sua escolha;

4) a estratégia: é o curso de ação que o tomador de decisão escolhe para atingir seus objetivos, dependendo dos recursos que pode dispor;

5) a situação: são os aspectos do ambiente que envolve o tomador de decisão, alguns deles fora do seu controle, conhecimento ou compreensão, e que afetam sua escolha; e,

6) o resultado: é a consequência ou resultado de uma estratégia adotada.

A tomada de decisão e a resolução de problemas podem ser abordadas de muitas formas. De acordo Caravantes, Panno e Kloeckner (2005), geralmente seguem a dois modelos: Racional e Comportamental, conforme apresentados no Quadro 1.

\section{Quadro 1: Modelo racional e comportamental de tomada de decisão}

\begin{tabular}{|l|l|}
\hline \multicolumn{1}{|c|}{ Modelo Racional } & \multicolumn{1}{c|}{ Modelo Comportamental } \\
\hline $\begin{array}{l}\text { 1. O tomador de decisões tem informações } \\
\text { perfeitas (relevantes e acuradas). }\end{array}$ & $\begin{array}{l}\text { 1. O tomador de decisões tem informações imperfeitas } \\
\text { (incompletas e possivelmente imprecisas). }\end{array}$ \\
\hline $\begin{array}{l}\text { 2. O tomador de decisões tem uma lista } \\
\text { exaustiva de alternativas dentre as quais pode } \\
\text { escolher. }\end{array}$ & $\begin{array}{l}\text { 2. O tomador de decisões não tem um conjunto completo } \\
\text { de alternativas ou não entende plenamente aquelas que } \\
\text { têm à disposição. }\end{array}$ \\
\hline 3. O tomador de decisões é racional. & $\begin{array}{l}\text { 3. O tomador de decisões tem uma racionalidade definida } \\
\text { e se restringe a valores, experiência, hábitos etc. }\end{array}$ \\
\hline $\begin{array}{l}\text { 4. O tomador de decisões sempre tem em } \\
\text { mente os melhores interesses da organização. }\end{array}$ & $\begin{array}{l}\text { 4. O tomador de decisões escolherá a primeira alternativa } \\
\text { minimamente aceitável. }\end{array}$ \\
\hline
\end{tabular}

Fonte: Caravantes, Panno e Kloeckner (2005, p. 455)

Em relação ao modelo racional, pode-se dizer que os tomadores de decisões possuem informações perfeitas e que são capazes de avaliar de forma sistemática e lógica cada alternativa existente. Neste caso, ao final, conseguem tomar uma decisão de maneira imparcial sobre o que será melhor para a organização. 
Contudo, as decisões racionais nem sempre são possíveis, pois fatores como emoções, preferências individuais e políticas da empresa acabam por interferir nesse processo, momento em que emerge o modelo de decisão comportamental. No modelo comportamental, o gerente muitas vezes terá que tomar uma decisão considerando sua percepção, experiência, informações e alternativas limitadas, o que não necessariamente poderá resultar em melhor resultado para a organização.

\section{O Processo Decisório}

Segundo Choo (2003), as decisões são resultado da adoção de um determinado curso de ação, e facilitam esta ação na medida em que definem e elaboram propósitos e alocam e autorizam o dispêndio de recursos. Desta forma, o processo decisório pode ser entendido como um conjunto de ações, que tem início bem definido e a partir deste início pode-se chegar ao resultado final desta ação.

O processo decisório pode ser definido como uma sucessão de etapas que levam à tomada de decisão e garantam sua implementação (CAMPOS, 2004). Essas etapas podem ocorrer de forma linear ou formalizada, e elas precisam ocorrer de maneira organizada e estruturada para que se possa atingir o resultado esperado.

Existem fatores que influenciam direta ou indiretamente no processo decisório. Um desses fatores é a incerteza, bem como a quantidade insuficiente de informações necessárias ao processo decisório. A incerteza pode representar riscos para a organização. Andrade (2000) conceitua risco como uma estimativa do grau de incerteza que se tem em relação à realização de resultados futuros almejados. Assim sendo, o risco sobrevém quando da incerteza de se prever os resultados.

O processo de decisão sempre foi algo desafiador para o administrador de uma pequena, média ou grande empresa, porque envolve habilidades, técnicas e competências, essas por sua vez intrínsecas ou desenvolvidas ao longo de sua experiência profissional. Maximiano (1995, p. 83) afirma que a tomada de decisão sob condições de incerteza, constitui-se em uma das habilidades mais importantes para um gerente. Assim sendo, o tomador de decisão assume um papel fundamental nas organizações, pois o processo decisório deve levar a organização à otimização de seus recursos, redução dos custos, elevação de desempenho e ganhos de resultados.

No processo decisório envolve-se sempre a qualidade da decisão que é considerado fator fundamental dentro da organização, porque pode afetar o futuro da mesma a curto, médio ou longo prazo. Deste modo, percebe-se que uma tomada de decisão envolve muito mais do que uma simples decisão, mas se a empresa continua com suas atividades ou não. Conforme destaca Maximiano (1995), a racionalidade do gestor é necessária nas tomadas de decisão, mas deverá estar em consonância com as informações advindas do diagnóstico do problema, bem como da análise e avaliação das alternativas, para evitar problemas superiores aos que deram origem ao processo decisório.

Nesta mesma perspectiva, conforme explicam Robbins e Decenzo (2004, p. 119), a modelagem teórica de processo decisório supõe que a tomada de decisão gerencial seja racional, no sentido de que os gerentes fazem escolhas consistentes, de valor maximizado dentro de restrições especificadas. Deste modo, a necessidade da decisão racional diante do cenário de incertezas em que a maioria das empresas estão 
inseridas, demanda do gestor a capacidade de compreender e avaliar adequadamente as alternativas existentes para uma melhor decisão para a organização naquele momento.

Algumas suposições de racionalidade são apresentadas por Robbins e Decenzo (2004) (Quadro 2), as quais constituem o modelo racional de processo decisório elaborado pelos autores.

\section{Quadro 2: Suposições de racionalidade do processo decisório racional}

\begin{tabular}{|c|c|c|c|c|c|c|}
\hline $\begin{array}{c}\text { O problema } \\
\text { é claro e } \\
\text { inequívoco. }\end{array}$ & $\begin{array}{c}\text { Uma meta } \\
\text { única e } \\
\text { bem } \\
\text { definida } \\
\text { deve ser } \\
\text { alcançada. }\end{array}$ & $\begin{array}{c}\text { São } \\
\text { conhecidas } \\
\text { todas as } \\
\text { alternativas e } \\
\text { consequências } \\
\text {. }\end{array}$ & $\begin{array}{c}\text { As } \\
\text { preferências } \\
\text { são nítidas. }\end{array}$ & $\begin{array}{c}\text { As } \\
\text { referência } \\
\text { s são } \\
\text { constantes } \\
\text { e estáveis. }\end{array}$ & $\begin{array}{c}\text { Não existe } \\
\text { nenhuma } \\
\text { restrição } \\
\text { de tempo } \\
\text { ou de } \\
\text { custo. }\end{array}$ & $\begin{array}{c}\text { A escolha } \\
\text { final } \\
\text { maximizará a } \\
\text { recompensa } \\
\text { econômica. }\end{array}$ \\
\hline \multicolumn{6}{c}{ TOMADA DE levam à: } \\
\hline
\end{tabular}

Fonte: Adaptado de Robbins e Decenzo (2004, p. 81).

Para os autores, a certeza de algo induz que um gerente possa tomar uma decisão adequada, porque o resultado de cada alternativa já se é conhecido. No entanto, no dia a dia das empresas, nem sempre as coisas ocorrem desta maneira. Nestes casos, a maior parte dos gerentes, portanto, precisam tentar atribuir probabilidades aos resultados que podem surgir, viabilizando assim a tomada de sua decisão. Quando tomadores de decisão, no caso gestores, não possuem conhecimento do problema e não conseguem determinar nem mesmo uma probabilidade razoável de resultados alternativos, eles precisam tomar sua decisão sob uma condição de incerteza (ROBBINS; DECENZO, 2004, p. 81).

Em síntese, pode-se dizer que foi o caso enfrentado por Leandro, gestor da empresa Ponto Certo equipamentos de informática. Os negócios estavam indo bem, de maneira satisfatória, sendo dependente de um cliente em potencial: a JDR/RS. Neste momento, Leandro não se preocupava em aumentar sua carteira de clientes, ou seja, não pensava em estratégias futuras para não depender somente da JRD/RS, acomodando-se no seu mercado de atuação. Quando "a chapa perdeu", se viu em um cenário de incerteza, que demandava a tomada de decisões diante de um ambiente de total incerteza, sem saber que decisão era a mais adequada para se tomar e o que deveria se fazer.

\section{Os Modelos de Tomada de Decisão}

Os modelos de análise dos processos de tomada de decisão, logo no início que começaram a prosperar, tratavam o processo decisório apenas como uma questão racional, em que as organizações deveriam tão somente serem baseadas na racionalidade dos gestores, bem como capazes de adaptar-se aos cenários no qual estavam inseridas. Em determinado momento, esses modelos passaram a serem questionados (OLIVEIRA, 2004).

Quando isso ocorreu, novos modelos foram surgindo para que fosse possível se compreender como ocorre a tomada de uma decisão, a partir do conhecimento do gestor. Alguns modelos são considerados mais flexíveis e adaptáveis a realidade das empresas. A fim de oportunizar a discussão sobre a abordagem destes 
modelos no contexto de tomada de decisão nas organizações, apresenta-se no Quadro 3 alguns dos principais modelos identificados na literatura.

\section{Quadro 3: Modelos de Tomada de Decisão}

\begin{tabular}{|c|c|}
\hline MODELOS & CARACTERISTICAS \\
\hline Racional & $\begin{array}{l}\text { O Modelo racional tem sua sustentação na teoria microeconômica neoclássica, onde a } \\
\text { racionalidade é o fator chave para a tomada de decisão. A informação objetivamente se } \\
\text { evidencia a lógica no processo decisório, em que o tomador de decisão não pode deixar } \\
\text { envolver-se por otimismo ou pessimismo (BERNSTEIN, 1997). }\end{array}$ \\
\hline $\begin{array}{l}\text { Carnegie ou } \\
\text { Racionalidade } \\
\text { Limitada }\end{array}$ & $\begin{array}{l}\text { O Modelo Carnegie ou Modelo da Racionalidade Limitada propõe que não é possível } \\
\text { para um tomador de decisões ter acesso a todas as possibilidades de ação, medindo } \\
\text { todas as opções, devido a impossibilidade física de ter acesso a todas as informações } \\
\text { e processá-las, além do alto custo envolvido nesse processo. O processo decisório é } \\
\text { feito de acordo com critérios específicos que limitam o processo de escolha e o número } \\
\text { de alternativas possíveis. Uma alternativa é selecionada entre as diversas propostas, } \\
\text { de acordo com o critério escolhido (MOTTA; VASCONCELOS, 2002). }\end{array}$ \\
\hline Incremental & $\begin{array}{l}\text { O modelo incremental analisa o processo de tomada de decisão como um exercício } \\
\text { prático de resolver os problemas mediante tentativas que podem ser de acertos ou } \\
\text { erros, ao invés de uma avaliação compreensiva de todos os possíveis meios. } \\
\text { Compreende-se que no processo de tomadas de decisão, as ações são diferentes das } \\
\text { utilizadas anteriormente, como forma de corrigir ou evitar erros pelas sucessivas } \\
\text { mudanças incrementais, levando a organização a um novo curso de ação (MOTTA, } \\
\text { 1988). }\end{array}$ \\
\hline Desestruturado & $\begin{array}{l}\text { O Modelo Desestruturado foi sugerido por Mintzberg (1995) que denominou as decisões } \\
\text { que não-programadas na organização, como decisões estratégicas não estruturadas. } \\
\text { Segundo esse modelo, no início do processo decisório, o administrador possui pouco } \\
\text { conhecimento do problema, das alternativas e das possíveis soluções. Assim, nesse } \\
\text { modelo, o processo decisório é caracterizado como dinâmico e com interferências. } \\
\text { Neste modelo, as fases que compõem o processo decisório são: Identificação, } \\
\text { Desenvolvimento e Seleção. Na fase de Identificação é efetuado o reconhecimento da } \\
\text { situação e o diagnóstico; já na fase do Desenvolvimento existem as rotinas, as } \\
\text { pesquisas por soluções alternativas e de delineamento e/ou o projeto da solução; a fase } \\
\text { da Seleção pode ser dividida em três etapas: pré-seleção; avaliação/escolha; } \\
\text { autorização. }\end{array}$ \\
\hline
\end{tabular}

Fonte: elaborado pelos autores a partir dos estudos de Motta (1988), Mintzberg (1995), Bernstein (1997), Motta e Vasconcelos (2002).

Os diferentes modelos de tomada de decisão apresentados no Quadro 3 são originados nos trabalhos de Lindblom (1959) e Simon (1971). Lindblom (1959) questiona os pressupostos da tomada de decisão racional, considerando "pretenciosa" a definição proposta neste modelo, de assumir que o gestor toma 
decisões a partir de uma avaliação ideal de todas as variáveis que influenciam o contexto de incerteza existente na organização. Conforme explica Simon (1971), o processo decisório ocorre naturalmente como o processo de pensamento e ação do ser humano, o que resultará em uma escolha do gestor. Neste caso, a racionalidade do gestor seria limitada (GONTIJO; MAIA, 2004).

De maneira geral, independentemente dos modelos teóricos desenvolvidos para a análise dos processos de tomada de decisão gerencial, observa-se que o sucesso das organizações depende do conjunto de decisões tomadas rotineiramente pelo gestor a frente do negócio. Assim, uma tomada de decisões adequadas tende a agregar valor as organizações. Em contrapartida, a tomada de decisões inadequadas pode comprometer a perenidade da empresa.

Desta forma, para que seja possível a tomada de decisões mais adequada as necessidades da organização, deve-se observar os vários fatores relevantes que podem impactar o futuro da empresa. Assim, antes de decidir por uma determinada situação, o gestor deve reunir e avaliar um conjunto de informações que the permita a decisão sobre qual das alternativas existentes é a mais adequada, tomando uma melhor decisão frente ao contexto observado. Adicionalmente, após a tomada de decisão, torna-se necessário o estabelecimento de um ambiente adequado de controle, capaz de fornecer informações que permitem o monitoramento e a avaliação da eficácia das estratégias implementadas pela empresa. 


\section{DESFECHO: O NOVO CENÁRIO DA EMPRESA APÓS A TOMADA DE DECISÃO}

Entende-se que as habilidades técnicas, capacidades e experiências dos gestores podem contribuir de maneira significativa para as organizações no momento da tomada de decisão. Assim sendo, especificamente no caso analisado, nota-se que a empresa Ponto Certo equipamentos de informática possuía em seu comando um gestor com habilidades e conhecimentos capaz de tomar melhores decisões para o desenvolvimento de sua empresa.

Quando iniciou sua organização, Leandro aproveitou o que estava dando certo em sua outra empresa que havia falido. Desta forma, constituiu uma nova organização com maiores chances de obter êxito no seu mercado de atuação. Após a sua expansão e a prospecção de novos clientes, Leandro consolidou a empresa Ponto Certo no segmento de locação e manutenção de equipamentos de informática. Assim, conseguiu captar importantes clientes.

Foi o caso da JDR/RS. Leandro dedicou-se a atender pessoalmente as necessidades desta empresa, na época seu principal cliente. Este atendimento diferenciado, contribuiu para que Leandro consolidasse esta parceria por longos oito anos. Mesmo sendo amigo pessoal do presidente da JDR/RS, Leandro só conseguiu mantê-la como cliente, em função da qualidade dos serviços prestados. Sem qualidade, não há parcerias sólidas!

Contudo, após captar este cliente, Leandro acomodou-se, deixando de avaliar novas oportunidades de negócios. Isto gerou uma dependência de sua empresa, pelo principal cliente. Neste caso, a dependência de um cliente é um aspecto que pode representar riscos ao negócio, uma vez que a perda de tal cliente, no curto prazo, pode impactar significativamente as atividades da empresa. Da mesma forma, a não captação de novos clientes estimula a concorrência a ingressar em um mercado de atuação pouco explorado, em que as demandas são crescentes.

Depois de tantas preocupações com o futuro da empresa, Leandro finalmente consegue enfrentar os problemas. Com a perda da eleição do candidato que o apoiava na JRD/RS, Leandro teve a atitude de recomeçar, contando com seu espírito empreendedor e sua força de vontade. Para tanto, importantes decisões foram tomadas, objetivando reposicionar a empresa no seu mercado de atuação.

O primeiro passo foi reconquistar aqueles clientes que a empresa havia perdido ou deixado de atender. Eram pequenos clientes, pequenos serviços, mas ao final, somava-se a um valor significativo, que anteriormente havia sido desprezado por Leandro. Iniciou-se então uma visita a cada um dos antigos clientes, com o intuito de trazê-lo novamente para sua empresa.

Neste momento, Leandro também começou a fazer visitas em empresas novas, com o propósito de divulgar seus serviços. Um ponto positivo que contava a favor para a empresa Ponto Certo era a reputação que a empresa tinha em seu mercado de atuação, que permanecia há quase 20 anos no mercado. Isto fez com que a empresa se tornasse conhecida, adquirindo confiança e legitimidade na região de atuação, pelo atendimento, qualidade e valor acessível de seus serviços.

Passados seis meses desde a eleição, como previsto, a empresa perdeu seu maior cliente. Porém, Leandro já comemorava que sua empresa não tinha fechado as portas e estava em pleno funcionamento, e ainda, atendendo quase cinquenta novos clientes. Para que isso ocorresse, é importante destacar que a empresa passou por uma grande reestruturação. 
No início, a Ponto Certo contava com uma equipe de 16 colaboradores. No entanto, teve que reduzir seu quadro para 5 colaboradores. Só no setor administrativo tinham 3 pessoas que faziam todo o trabalho, ficando somente uma colaboradora. Infelizmente aconteceu o que Leandro não queria: redução no seu quadro de funcionários. Contudo, todo o processo possibilitou que ocorresse de maneira rápida uma reestruturação na empresa que por consequência foi muito positiva, uma vez que viabilizou a continuidade das atividades da empresa.

A mesma buscou diminuir custos, teve um controle maior com gastos relacionados à luz, água, telefone, internet, entre outros gastos. Tudo isso era preciso e foi importante para que a empresa continuasse atuando. Leandro estava contente e confiante, porque a empresa está seguindo em frente, algo que até então ele achava impossível de acontecer se perdesse seu principal cliente: a JRD/RS.

Leandro também iniciou um trabalho de reaproximação com a nova presidência da JRD/RS. Como tinha um bom histórico de prestação de serviços durante os últimos 8 anos, Leandro agendou uma reunião com o novo presidente da JRD/RS e conseguiu um novo contrato, com valores menos atrativos para a Ponto Certo, mas que possibilitavam a empresa continuar com uma boa rentabilidade e gerasse novos empregos. O processo da renovação do contrato com a JRD/RS ocorreu aproximadamente seis meses após a troca de presidência. Assim, além de continuar atendendo a JRD/RS, mesmo que por um valor menor, a empresa ainda passou a valorizar a conquista de novos clientes.

Em face das ações tomadas por Leandro no processo de reestruturação organizacional, ao final de doze meses a empresa Ponto Certo conseguiu atingir uma carteira de cento e trinta novos clientes, e ainda conseguiu continuar prestando seus serviços a JRD/RS. Toda esta situação fez com que a empresa sofresse um grande impacto.

As ameaças muitas vezes são transformadas em oportunidades e foi isso que aconteceu com a empresa Ponto Certo. Leandro, diante de grandes incertezas, precisava tomar importantes decisões no seu negócio. Graças a sua expertise, sua experiência e a excelência de seus serviços, conseguiu reverter à situação a seu favor. Recentemente Leandro revelou o novo cenário financeiro de sua empresa, como se observa no Tabela 2.

Tabela 2: Novo cenário financeiro - faturamento trimestral da Empresa Ponto Certo

\begin{tabular}{c|c|c|c|c|c}
\hline Período & $\begin{array}{c}\text { Faturamento com } \\
\text { Cliente JRD/RS }\end{array}$ & $\begin{array}{c}\text { Participação } \\
\text { no } \\
\text { Faturamento } \\
\text { Total }\end{array}$ & $\begin{array}{c}\text { Faturamento } \\
\text { com Demais } \\
\text { Clientes }\end{array}$ & $\begin{array}{c}\text { Participação } \\
\text { no } \\
\text { Faturamento } \\
\text { Total }\end{array}$ & $\begin{array}{c}\text { Total do } \\
\text { Faturamento }\end{array}$ \\
\hline Janeiro & $\mathrm{R} \$ 23.103,78$ & $30,60 \%$ & $\mathrm{R} \$ 52.400,00$ & $69,40 \%$ & $\mathrm{R} \$ 75.503,78$ \\
\hline Fevereiro & $\mathrm{R} \$ 21.426,00$ & $30,04 \%$ & $\mathrm{R} \$ 49.902,56$ & $69,96 \%$ & $\mathrm{R} \$ 71.328,56$ \\
\hline Março & $\mathrm{R} \$ 22.235,00$ & $29,39 \%$ & $\mathrm{R} \$ 53.411,25$ & $70,61 \%$ & $\mathrm{R} \$ 75.646,25$ \\
\hline
\end{tabular}

Fonte: Adaptado pelas Autoras de Relatórios Gerenciais da Empresa Ponto Certo Equipamentos (exercício 2015).

Atualmente, a empresa trabalha no desenvolvimento de um Plano de Desenvolvimento Estratégico para projetar suas ações para os próximos 5 anos.

\section{Questão para discussão}

Diante do desfecho apresentado, que decisões tomadas por Leandro foram relevantes para impulsionar/alavancar a empresa? 


\section{REFERÊNCIAS}

AMBURGEY, T. L.; KELLY. D.; BARNETT. W. P. Resetting the Clock: The Dynamics of Organizational Change and Failure. Academy of Management Proceedings, n. 1, p. 160-164, Aug., 1990.

ANDRADE, E. L. Introdução à Pesquisa Operacional: Métodos e Modelos para Análise de Decisão. 2 ed, Rio de Janeiro: LTC, 2000.

ANSOFF, H. I. Estratégia empresarial. São Paulo: McGraw Hill, 1977.

AVEY, J. B.; WERNSING, T. S.; LUTHANS, F. Can positive employees help positive organizational change? Impact of psychological capital and emotions on relevant attitudes and behaviors. The Journal of Applied Behavioral Science, v. 44, n. 1, p. 48-70, 2008.

BERNSTEIN, P. L. Desafios aos Deuses: A Fascinante História do Risco. Rio de Janeiro: Campus, 1997.

CAMPOS, C. M. Transição do Modelo Organizacional Tradicional ao Pós-Industrial na Administração Pública do Estado de Santa Catarina. 2004. 83 f. Dissertação (Mestrado em Engenharia de Produção) - Centro Tecnológico, Departamento de Engenharia de Produção, Universidade Federal de Santa Catarina, Florianópolis, 2004.

CARAVANTES, G.; PANNO, C.; KLOECKNER, M. Administração: Teorias e Processo. São Paulo: Pearson, 2005.

CHIAVENATO, I. Administração nos novos tempos. 2 ed, Rio de Janeiro: Elsevier, 2004.

CHOO, C. W. A Organização do Conhecimento. São Paulo: Editora SENAC São Paulo, 2003.

GONTIJO, A. C.; MAIA, C. S. C. Tomada de decisão, do modelo racional ao comportamental: uma síntese teórica. Cadernos de Pesquisas em Administração, v. 11, n. 4, p. 13-30, Out./Dez., 2004.

HALL. R.H. Organizações: estruturas, processos e resultados. São Paulo: Prentice Hall, 2004.

KIEFER, T. Analyzing emotions for a better understanding of organizational change: Fear, joy, and anger during a merger. Managing emotions in the workplace, p. 45-69, 2002.

LEWIN, K. Frontiers in-group dynamics II. Channels of group life; social planning and action research. Human Relations, v. 1, n. 2, p. 143-153, 1947.

LIMA, S. M. V.; BRESSAN, C. L. Mudança organizacional: teoria e gestão. Rio de Janeiro: FGV, 2003.

LINDBLOM, C. E. The Science of Muddling Through. Public Administration Review, v. 19, p. 79-88, 1959.

MAXIMIANO, A. C. A. Introdução à Administração. 4 ed. São Paulo, Atlas, 1995.

Introdução à Administração. 3 ed.. São Paulo: Compacta, 2009.

MINTZBERG, H. Criando organizações eficazes: estruturas em cinco configurações. Tradução: Cyrus Bernardes. São Paulo: Atlas, 1995.

MOTTA, P. R. Razão e Intuição: Recuperando o llógico na Teoria da Decisão Gerencial. Revista de Administração Pública, v. 22, n. 3, p. 77-94, Jul./Set., 1998.

MOTTA, F. C. P.; VASCONCELOS, I. F. G. Teoria Geral da Administração. São Paulo: Pioneira Thomson Learning, 2002.

NETO, A. A. A Dinâmica das decisões Financeiras. Caderno de Estudos, v. 16, p. 9-25, Jul./Dez., 1997.

OLIVEIRA, D. P. R. Sistemas de informações gerenciais: estratégicas, táticas e operacionais. 9 ed São Paulo: Atlas, 2004.

ROBBINS, S. P. Administração: mudanças e perspectivas. São Paulo: Saraiva, 2000.

ROBBINS, S. P. E DECENZO, D. A. Fundamentos de Administração: conceitos e aplicações. São Paulo: Prentice Hall 2006.

ROBBINS, S.; JUDGE, T.; SOBRAL, F. Comportamento organizacional: teoria e prática no contexto brasileiro. 14. ed. São Paulo: Pearson, 2010. 
AMANDA PATERNO SBISSA, PATRINÊS APARECIDA FRANÇA ZONATTO, SIDNEI VIEIRA MARINHO, ANETE ALBERTON

RONDEAU, A. Transformer l'organisation. Comprendre les forces qui façonnent l'organisation et le travail. Gestion, v. 24 , n. 3, p. 12-19, 1999.

SIMON, H. Comportamento Administrativo. Rio de Janeiro: FGV, 1971.

VERGARA, S. C. Gestão de pessoas. 2. ed. São Paulo: Atlas, 2000. 